\title{
Research on the Attitudes of the Directors of Croatian State Archives to Planning and Implementing Volunteer Management
}

Preliminary communication _ DOI 10.22522/cmr20160210 _ received on 3 October 2016 UDK 001.891:316.64 _ 659.44:364.467

\section{Goran Pavelin}

University of Zadar, Zadar, Croatia. Email: gpavelin@unizd.hr

\section{Roko Matanović1}

University of Zadar (student), Zadar, Croatia. Email: rokomata@hotmail.com

\section{Abstract}

Croatian archives have stayed out of the spotlight for the most part, opting to use government subsidies as a crutch to help them go about their business without paying much attention to economic realities. As a terrifying result, archive repositories are fraught with data and records that have not been properly sorted out and made available for public use yet. To make things worse, few citizens feel like paying the local archives a visit as they are not sure what value they might get for their time. This paper deals with a twofold approach (legislation and education) to getting archives management up to date with modern practice and also reveals why Croatian archives have been slow to change, unable to cope with their biggest setbacks. Empirical data suggest managers are ill-equipped to run a volunteer management programme, let alone carry out basic PR activities to let taxpayers know for what services they are funding the archives. According to survey results, managers would very much like to be taught how to make their tenure more successful. The paper is also ground breaking in that no other research has been done before on Croatian archives being in tune with the modern practice of volunteer management.

Keywords: archives, director communication skills, relationships with stakeholders, volunteer management

1. While attending the course Basics of Public Relations in the second year of the undergraduate study programme Culture and Tourism, the student (the first of the above-mentioned authors) participated in a project led by the professor. 


\section{Introduction}

Croatian archives are overwhelmingly funded by the government, which makes them beholden to taxpayers who find it in their best interest to shed light on whether current Croatian archival practice has led directors to unwittingly mismanage the funds that are at their disposal. If Croatian citizens make no effort to keep a track record of such institutions and put them under tight scrutiny, there is no guarantee that the money given to archives is well spent. Comparing the state of archival practice to leading authors' guidelines for improvement can give concerned citizens all the answers they need as to what action should be taken.

The archive activity is located within the organization of the Ministry of Culture of the Republic of Croatia, in one of the services in the Sector of Performing, Museum and Archival Activity, within the framework of the administration for the development of culture and art. The above-mentioned Ministry is responsible for the legal supervision of the state archives, while the work of the other archives is under the supervision of the administrative body of the county or the city of Zagreb, which is responsible for culture. Professional supervision of the regional state archives is exercised by the Croatian State Archive as the parent institution, whereas the Ministry of Culture is responsible for the professional supervision of the Croatian State Archive. The role of the Croatian Council of Archives is that of advising the Minister of Culture on the development and carrying out of the work, as well as on the performance of individual professional activities (Ivanović, 2010, p. 259).

Archives are institutions that preserve the national heritage. Archive material relates to all levels of society as well as to the general value which it has as a cultural good or heritage. Along with scientific appraisal, the highest value of the material is its connection with the culture, origin and identity of a people. The cultural purpose of archives implies the use of material in its broadest anthropological sense to indicate the totality of symbols and signs that today give meaning and substance to human life and enables them to be transmitted to subsequent generations (Joyce, 1984; Pavelin, 2013).

Research on the need for information indicates that, hierarchically viewed, it is set similarly to Maslow's general theory of needs. The need for information is just as vital as the need for food and drink, even for ordinary people, because individuals like to control their own 
environment. In the sphere of information, speaking of services, immaterial products become the key factor, and this is a reference service. The information service of an archive is defined by its own goals and the goals of its national parent organization, but also by the requirements of different users. This also includes staff, without whom there would be no satisfactory exchange with the public, the archival service price and finally finding the most optimal way of communication with users. Archives within the system of information services realize the necessity to rationalize their own business activities in terms of making progress, quite often simply to survive (Pavelin, 2016; Rjean, 1988).

\section{Communication and management skills of archive directors}

Today's archives compared to libraries and museums still have a specific and somewhat different relationship with the general public. Research focused on the users indicates that an archive cannot operate in isolation (Williams, 2006, pp. 148-149; Pavelin, Pletikosić, 2014, pp. 32-34). Organizations have much more responsibility towards the public, who want to know what they stand for and what kind of influence they exert on society and the environment (Gregory, 2006, p. 19). The Croatian State Archive is managed by the Director (Ivanović, 2010, p. 259). According to the "Law on Archival Documentation and Archives", there are no other administrative, advisory or supervisory bodies. Managing human resources is a sensitive segment, which Croatian archivist Ivanović leaves to the director/ directors of the archival programme (Ivanović, 2010, pp. 169-175). This author mentions competencies, staff involvement, cooperation, motivation, organizational culture, and support for the realization of the set objectives. The same author argues that managing an archive programme is a complex but a worthwhile task, which requires a more systematic and comprehensive approach. However, this performance is the responsibility of the person in charge, not specifically of the appointed director of the archive (Ivanović, 2010, pp. 12, 41).

American literature on archives assigns archival directors the role of a manager. Thus Bradsher (1988) criticizes archival managers because they quite often do not have an articulated, understandable or clear vision, they fail to provide guidelines and instructions for their institutions in order to inspire their employees and they show lack of commitment 
and concentration on the essentials. The likes of such managers become commanders who give orders instead of being leaders, very often forget that the staff do not work for them but with them (Bradsher, 1988, p. 254). The problem with the archive management is obvious in the culturally defined differences relative to business ethics, money and authority. Still, to those who successfully integrate archival and management skills, awards are important in terms of the programme success and professional development (Kurtz, 1988, p. 242). The effectiveness of communication management requires a solid understanding of the archival programme, and by analogy, the dynamics of the competent authority or supervisory board, as well as the external public. Communication managers build an influential base, understand the limitations and the existing possibilities, and take risks on the basis of circumstances (Pavelin, 2016a).

\section{Defining Stakeholders of Archival Institutions}

Organizations in the public sector are characterized by a mission of providing services and support to the life of citizens. Public sector organizations provide health care, national security, safe environment, education, arts and culture, etc. (Cutlip, Center, Broom, 2003, p. 437). Archives have a mixed clientele whose needs they should satisfy. They have multiple objectives and have to determine the relative importance of everyone.

Archivists have to prioritize their decisions in order to focus on groups that most need their material and attention. The most important goal of public relations is communicating and fostering relationships with their stakeholders. Stakeholders involve those with a financial interest (including taxpayers in relation to public services), office holders (politicians, board members), administrators, employees, suppliers, buyers and local communities. In archival services there are two additional groups of stakeholders, i.e. the creators and donors of materials to the archive, and future users, for whom the material is preserved (Williams, 2006, p. 209). The authors approach researchers with the intention of observing them as stakeholders and attempt to reveal the nature of interest of each group of stakeholders in archival services. The relationships between stakeholders and archives is the most successful when there is mutual trust and benefit on both sides (Lamb, McKee, 2005, pp. 141-144). 


\section{Volunteers as a Target Group of Archive Communication Activities}

Influential stakeholders may subsequently enhance their involvement in the organization and offer more working hours and money, which makes them great promoters in the circle of their acquaintances. If we take the example of a study conducted in the United States in the 1980s (Dearstyne, 1987; Settani, 1985), we learn that archive material was used very little. The key reason for this problem, according to archivists, was a lack of resources such as money and staff. We might conclude that the public will never use this material, as they are not even aware that it exists. Statistical data about the Croatian State Archives is given by the National Institute for Statistics of the Republic of Croatia. According to the data report available on the Webpage of the Centre of Croatian Culture, the updates about Croatian cultural statistics and the statistics about cultural activities can be found, however, from the year 2011 (http://www.culturenet.hr). According to the list of archive holdings, collections and material from 2011, and the total amount (in meters, hours and units) of processed material, we can determine the total amount of unprocessed material in all Croatian archives. The obtained data are presented in a table as follows:

Table 1: Unprocessed material according to the Croatian archival holdings and collections as found in 2011, expressed as a percentage

Archival material (Name)

Societies, associations, affiliations

Landed gentry, family and personal holdings

Collections of additional copies of archival material

Health care and social services

Culture, science, information

Judiciary

Political parties, DPO and trade unions

Collections of original archival records

Economy and banking

Administration and public services

Education

Religious institutions

Sound recordings

Military units, institutions and organizations

Film material
Unprocessed material calculated as

a percentage

$51 \%$

$46 \%$

$41 \%$

$40 \%$

$39 \%$

$36 \%$

$36 \%$

$34 \%$

$30 \%$

$30 \%$

$20 \%$

$17 \%$

$8 \%$

$7 \%$

$6 \%$ 
It is obvious that the Croatian state archives face the same problems as their foreign counterparts. However, foreign archives have recently been considering seeking additional forms of support for human resources, i.e. planning and launching new projects based on volunteer management.

\subsection{Planning and Volunteer Inclusion in Archive Programmes}

Planning a volunteer programme for Croatian archives could be considered a milestone per se as virtually no localized manuals or handbooks have been written for management to take advantage. Authors like Bunić (2010) and Faletar (2002) have only dug into volunteer management for libraries and museums but merely scratched the surface as there is little talk of nurturing public relations which are key to bringing today's non-profit organizations a step closer towards meeting their goals. Furthermore, most papers on Croatian archives may very well be outdated given that leading institutions such as the Society of American Archivists (2014) have recently laid out new guidelines for volunteer management and the papers do not address non-profit organizations' need for an overhaul of their business strategy that has monumentally failed to reach out to the public.

A modestly used possibility achieves real values first with the evaluation of archival needs, and following it with a decision on whether volunteers are a suitable replacement in the job of archivists as qualified staff (Ivanović, 2010, pp. 217-218).

Hiring volunteers into non-profit organizations such as archives is generally speaking well within the bounds of law, as evidenced in Chapter 7, Paragraph 2 of the Croatian Volunteering Act, although rolling out a volunteer management programme for archives is an uphill battle as legislation fails to work out the details and leaves the development of such programmes trapped in legal limbo, all courtesy of a Parliament that could not care less.

\subsubsection{Evaluating the Archive Needs for a Volunteer Programme}

It should be primarily determined whether volunteers can help reach the defined goals and the mission of the archive. In order to make the work with volunteers successful, it is 
necessary to design a volunteer programme which will connect the archive strategy, its vision, mission and values to volunteers and all that they would bring into the organization (for instance, association with new resources and media, political donors, enthusiasm for work, personal skills, experience and talents) (Jurić, 2007, pp. 33-35).

It is extremely important to set reasonable expectations from volunteers, in the sense that they know exactly what they should achieve and what obstacles they might encounter on their way to obtaining the organizational goals. We know that volunteers invest time and effort in a certain project without claiming a financial reward for their work, but the organizational structure which is established during the volunteer's involvement certainly requires money and other resources.

\subsubsection{Planning an Archive Volunteer Programme}

Archives should carefully plan volunteer programmes and have good volunteer managers: from external agencies for public relations or a person such as the director, or search through external services via the Croatian volunteer centres (Split, Rijeka, Zagreb and Osijek form a network of volunteer centres). There are four key elements to planning for archives: 1) selection of volunteer coordinator, 2) work description, 3) security guarantee, 4) determining accountability.

(1) The first step in the activity of planning is to appoint a volunteer coordinator or manager, who would begin to supervise the volunteer programme. The coordinator should be convinced of the effectiveness of the volunteer programme and skilful at interacting with other people, be able to closely cooperate with archivists in defining the tasks and aligning them with the volunteer work, and be a link between paid and unpaid staff.

(2) The list of task distribution for the volunteer programmes comes gradually and rationally. The volunteer must have a reserved work space like paid staff. The title of the position has to be precise. The title of the position helps archivists to understand the role assigned to the volunteer. It gives a sense of identity to the volunteer.

(3) With unpaid staff, the archive also has to consider the matter of security. If the volunteer programme involves handling valuable documents, remarks of the entire archival community should be taken into account. In short, the security measures of the volunteers who deal 
with restrictive, reliable and valuable documents might be identical to the measures relating to the staff.

(4) When planning a volunteer programme, it is necessary to investigate possible accident and liability insurance. If volunteers become a new addition to individual archives or when the volunteer programme is already being implemented and the matter of security is still not being considered, we have to immediately contact the administration or a lawyer because of the need for insurance coverage (Randle, 2003, p. 86).

\subsection{Organizing in Volunteer Management}

Volunteers readily accept and disclose the objectives of the organization to the community in which they live, and they do this with great enthusiasm, especially in the public sector. Most involved volunteers reside in the community and are part of that community; they present the organization to the community, and thus simplify the interaction between the community and the organization (Connors, 2011, pp. 56-59). Volunteering in the Croatian State Archive can be organized in two ways: 1) the archive sends out an invitation for volunteering to students. The students who accept the invitation will attend an interview and find out the following: how many hours a week they would have to volunteer, which tasks they would have to perform, and how long the overall engagement would last. After the volunteer's contract has terminated, the archive has to issue a volunteer certificate. The student then submits the certificate to the Secretary of their University department and it will subsequently be recorded in the Diploma Supplement.

(2) The alternative way involves drawing up a syllabus which will estimate the number of work hours and, according to the student's workload, the corresponding ECTS credits.

According to the University procedure, the syllabus is forwarded to the Professional Council of the Department in which the professor is employed. If it is adopted, it will be then included in the schedule of the relevant study programme starting the following year. The leader of the course has the task to arrange the details of the student's work together with the representatives of the archive. While the former way requires more effort from the archive, the latter requires more effort from the university staff (Kotlar, 2013). 


\subsection{Recruitment of Archive Volunteers}

Recruitment means attracting volunteers with an offer of the already defined positions. Potential sources for archive volunteer recruitment are numerous civic and professional organizations, senior citizen groups, as well as various historical and genealogical societies. Partnership with these groups enables the archive to develop unlimited convenience in seeking volunteer help. It is important to focus on the archive material, which is potentially attractive to a number of people who have special interests: thematic or career - for working with historical material.

\subsubsection{Designing Messages and Attracting Volunteers}

In their search for volunteers, Croatian archives may include their users, especially current and future researchers. To be certain about the choices, students of librarianship, archival science and history are selected. However, the coordinator could also consider taking students who are willing to help from other areas.

Each recruitment message should contain a description of the problem to be solved, a description of the ways in which the volunteer at work can solve this problem, the answer to possible doubts about the volunteer's application for the position, information about training and awards which will be given, and contact information for further questions (Jurić, pp. 41-49). The message can be sent out by word of mouth, printed material, through the local media, via volunteer centres and at certain public events.

\subsubsection{Interview with Potential Volunteers}

Each potential candidate attends a personal interview, which is just as necessary as an interview for paid staff members i.e. archivists. The candidate should not be made to feel that the interview is an interrogation, but rather that is a time for both parties to get acquainted. The interview also gives an insight about what the volunteer expects from the archive for his/her service. The coordinator should explain all possible volunteer assignments, the training that will be required, the length of service and schedule of the volunteer's 
requirements, as well as the procedures of security management. Careful selection of volunteers prevents many problems in volunteer management. We should also be able to say no to unsuitable candidates.

\subsubsection{Orientation and Volunteer Training}

The supervisor facilitates the effectiveness of a large part of the planned volunteer work, because he/she thinks in terms of the project, decides what the volunteer will do, helps to define the training and keeps to the procedures of supervision. Before beginning training, it is necessary for every volunteer to know some basic facts about the archive such as its history, the kinds of materials collected, their subject and sources, its relationship with the parent organization, its allocation and funding, the nature of the archive's users, the organization and work of each section, the number and responsibilities of the staff and the line of supervision, as well as the contribution that archivists make to the archive. Experience of archive work with volunteers has shown that they are a kind of assistance useful and valuable for the participants. The effective work performed by archive volunteers may also be tabulated:

Table 2: Effective work performed by archive volunteers

Source: Adapted according to: Pederson, 1993, p. 343

Function

Material protection

Processing and describing material

Office service Education and public
relations

General administrative support

\section{Activities}

Refilling staples, re-storing material, maintaining and cleaning documents, closing material

Indexing information aids, newspapers, bulletins, interviewing topics from oral history, preparing special lists and bibliographies

Ancillary office staff supervising the use of materials; photocopying, registration, orientation of new users, teaching the use of information aids, stacking leaflets and putting equipment and tools in order

Guiding tours of archive premises and exhibitions; writing articles; giving talks about services, collections and research methods; updating contact lists; helping to send brochures by email and organizing special events, proofreading.

Performing secretarial tasks (telephoning, photocopying, typing/ proofreading texts); administrative tasks 
A practical complement to the volunteer programme may be embodied by creating a good manual, which will be drawn up by the whole archive community. This manual would be given to each volunteer, who would get acquainted with the above-mentioned basic information; it may also contain a welcome letter from the director of the parent institution or the archive director, as well as the archive's leaflets with a list of its holdings and collections.

\subsection{Management of Volunteer Work}

The most common reason for which volunteers lose interest in or leave the job is that they receive little or no supervision. There is a lack of reports about volunteer training. The volunteer's work should be checked and errors corrected and the answer to whether they are doing a good or a bad job can be given by the supervisor.

\subsubsection{Supervision and Monitoring}

Supervision presupposes a transactional model of communication which emphasizes the importance of relationships, processes, content and context i.e. the basic axioms which are dealt with by the theory of communication. What becomes important in the process of supervision is interpersonal relationship and communication. In interpersonal communication, the process of creating and exchanging meaning, which is a two-way, multidirectional, permanent and cumulative process, takes place (Laklija et al., 2011, pp. 365-382). Volunteers do not only work; they observe, produce new ideas, communicate with the community and receive feedback.

There are, however, situations when a volunteer will not meet the supervisor's standards of performance and problems may also arise with other volunteers and supervisors. If the problem is in the supervisor, the only option is to assign supervision to someone else or change the volunteer tasks. If the problem is created by the volunteer, then the time may have come to end the partnership. 


\subsubsection{Risk Management}

The simplest principle for determining the necessary level of supervision requires the following: the more dangerous and uncertain for the volunteer's general welfare the nature of work is, the more cautious the organization needs to be. Risks may arise from the volunteer's area of work, the organizational assets (furniture, vehicles, equipment, electronics, computers, manuals) income (investors, donations), reputation and criminal liability. Given an awfully large number of accident sources, a smart manager will set up a group for risk management and gather people from different areas of expertise at the same table (representatives of firefighting, police, human resources and legal officials, investment advisors, consultants for safety at work, etc.), who would make it easier for him/her to consider and cope with all types of risk at work (Connors, 2011, pp. 335-343).

\subsubsection{Rewarding Volunteers}

Recognition begins by making it clear to the volunteer that he/she is part of the archival community, not just an external associate who helps to do work, but feels neglected by the staff. It is necessary that recognition fits the wishes of volunteers and the style of the archive. The ceremony of presenting the volunteer with an award is also a form of communication, which acknowledges the contribution made by the volunteer to the organizational goals. Holmes and Smith (2009, pp. 121-125) argue that too much emphasis on material rewards may take us in the wrong direction, since volunteers today appreciate more a thank you letter and pay more attention to research. The best solution would be to find the most balanced ratio of the benefits and costs from employing volunteers.

\subsubsection{Evaluation of Volunteers and Archives}

The manager who establishes a communication link between the interest groups and the evaluation programme will certainly find it easier to understand and support a volunteer programme. Since excessive adulation for all interests undermines a good evaluation, the manager tries to find out which individuals or groups have the biggest impact on the future of the programme and adjusts the evaluation so that they find it legible and understandable. 
From the preserved statistical data of published volunteer tasks, we can justify the time invested in the training and supervision of volunteers, as well as for other purposes. From the records of working hours, clocking in and out, and the hours of work done, data relevant to the evaluation of the voluntary programme are collected. Notes of frequent absence from work, being late or leaving the archive earlier may indicate a loss of the volunteer's interest in his/her work assignment.

\section{Research of the Attitudes of the Directors of Croatian State Archives to Volunteer Management}

\subsection{Defining the Research Problem}

Introduction of volunteers in the work of archival institutions is at present a relatively new concept in Croatia, even though volunteers in the world today are a very common labour force, which does not require high financial rewards since they enter into the relationship with a non-profit organization as highly motivated, and under the watchful eye of the Management Board may remain for a longer period of time. In order to be able to use volunteers, Croatian archives should have a well-developed plan of volunteer management and professionals in public relations to maintain good communication with the society from which future volunteers are selected, but also with permanent staff members, whose performance of daily duties must not be hampered by the arrival of volunteers. The directors themselves are expected to be aware of the benefits and drawbacks of using volunteers in terms of costs, material security, which they have to guarantee, and the reputation of the institution, which is based on the treatment of volunteers.

\subsection{Research Objectives}

In order to complete the knowledge of the practice of Croatian state archives, we focused on:

- Whether the archives have already dealt with volunteers in their work

- Whether archives have a previously designed plan of volunteer management 
- What the directors' thoughts are about the cost-effectiveness and risk of hiring volunteers

- What channels and methods of communication with volunteers they prefer

- Directors' competencies for volunteer management and their wishes for reforms in archival practice

\subsection{Determining the Research Question}

Having looked at the global trends in achieving the objectives of non-profit organizations via volunteers, who recognize the opportunity to fulfil their desire to serve the community, the following question arises: Are Croatian archives ready to introduce volunteers in their archives and among archivists?

\subsection{Methods}

The research was conducted on a sample of 14 archival institutions, whose activity is legally registered in the Republic of Croatia. The contact with the archives had been previously established by phone, and with the consent of the directors, an electronic questionnaire was compiled and sent out. The anonymous questionnaire consisted of simple, dichotomous questions, expressing the degree of agreement with the items, using a Likert scale and multiple choice questions. Methods used in the processing of the results obtained were the arithmetic mean, the median, the mode and the standard deviation.

\subsection{Results}

The anonymous questionnaire comprised of 17 questions, of which the first was:

1. Have you ever during your mandate hired volunteers in your staff? 
Table 3: Have you ever during your mandate hired volunteers in your staff?

Yes

$71.4 \%$ of respondents reported that they had never had volunteers in their ranks. The arithmetic mean of the result obtained was 1.71, the median 2 , the mode 2 and the standard deviation 0.47 . The above-mentioned answer was in line with the expectations of the research team. The following question asked respondents whether they agreed with the item that the involvement of volunteers would threaten the security of their archive. The dominant response (51.1\% of all responses) was "I neither agree nor disagree" indicating that the directors were hesitant to use volunteers, as they were aware of the benefit that such a labour force would bring, but also of their responsibility for the archive material. The standard deviation was 1.07 , that is, the rest of the answers were equally distributed on the Likert scale. The third question related to the cost-effectiveness of hiring volunteers (invested effort, resources and time), as seen by the archive directors. The arithmetic mean of the result obtained was 2.78 , the median 3 , the mode 3 and the standard deviation 1.37. Namely, the minimum majority of respondents opted for "I neither agree nor disagree", which most likely stemmed from the data obtained from the first question, which was that only $28.6 \%$ of surveyed archives had had previous experience with volunteers, so here the directors could not strongly confirm or deny the fact that volunteers required too much time and money to be introduced in their work environment in terms of quality. The fourth question touched the national archives management i.e. how they would, according to respondents, react to the initiative of hiring volunteers.

The arithmetic mean of the results obtained was 4.07 , the median 4 , the mode 5 and the standard deviation 1.14. The graph shows that most respondents believed that the 


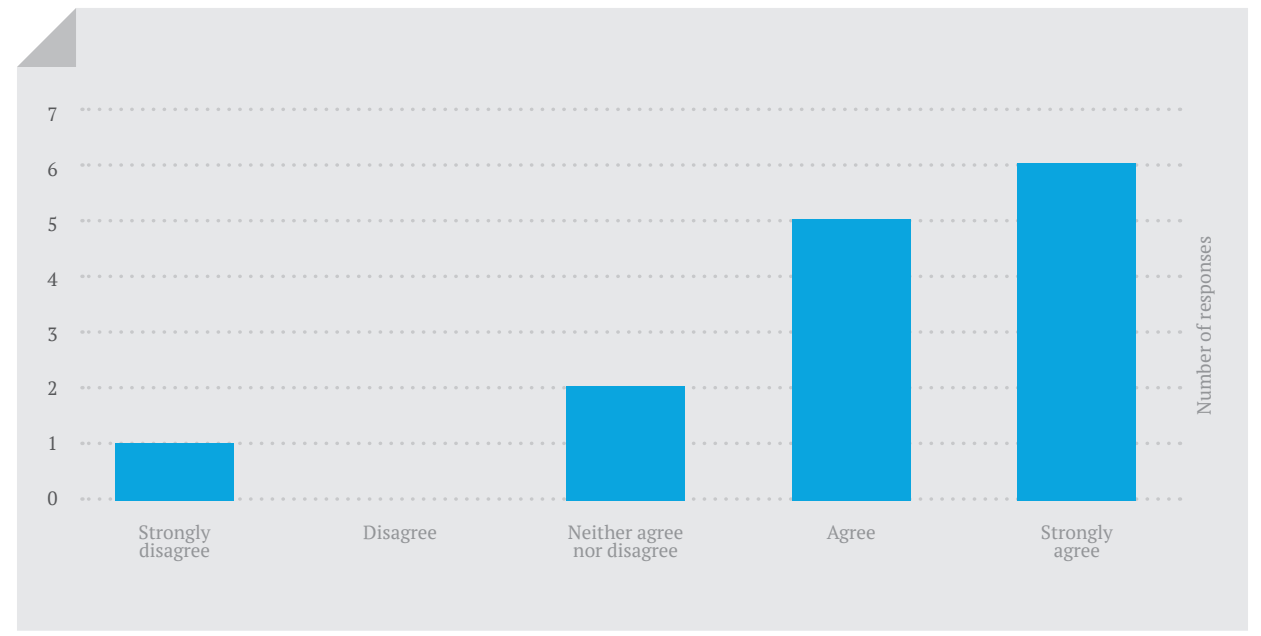

Figure 1: Rating of directors' attitude to the support of the national archive management for the branch's plans to hire volunteers

National Archive Management (Croatian Council of Archives) did not very much object to involving volunteers in the work of archives, which excludes the previously mentioned factor of authority as the culprit for having ignored so far the possibilities of volunteer services. Therefore, the fifth question asked respondents to judge whether he/she was the most suitable person for coordinating the work with volunteers, to which the majority of the sample (42\%) agreed, while the other respondents disagreed or remained neutral. The arithmetic mean of the results obtained was 4 , the median 4 , the mode 4 and the standard deviation 0.78 . The implication is that directors are not sufficiently confident about their own competencies for managing volunteers and they are not willing to relinquish such an important business function to another employee. The following question concerned the quality of the possible or already realized cooperation between permanent staff and volunteers. The arithmetic mean of the results obtained was 3.71, the median 4 , the mode 4 and the standard deviation 1.14 . Here, the majority of respondents argued (28.6\% of those who strongly agreed and $35.7 \%$ of the surveyed agreed with the item) that such cooperation would develop without difficulty.

The seventh question, on rating attitudes, read as follows: The problem of the security of archives may be solved by supervising and mentoring volunteers in such a way that I select my archivist who would be the supervisor. 
Table 4: The problem of the security of archives may be solved by supervising and mentoring volunteers in such a way that I select my archivist who would be the supervisor.

Strongly disagree

Disagree

Neither agree nor disagree

Agree

Strongly agree

Mean

Median

Mode

Standard deviation

The arithmetic mean of the results obtained was 3.36, the median 3, the mode 3, and the standard deviation 1.22 . Namely, $35.7 \%$ of respondents did not have a concrete stance on the above-mentioned item, and the other responses (21.4\% disagreed and the same percentage strongly agreed) prevailed in favour of a positive attitude. It is obvious that there is a sceptical current of directors who do not trust their own employees to relinquish the care of volunteer work supervision due to the valuable archival material held by the archive which he/she manages. In the following question, respondents were asked to give a concrete answer whether they even had a programme designed for the organization of volunteer work, employment, training, supervision and control. The great majority responded negatively (12 archives), and the other answers indicated that they had such a plan and they had hired volunteers during their mandate i.e. they expressed a certain level of interest in volunteers' involvement in the archive work. Question nine was an attempt to find out what target groups in society respondents would prefer to hire. They were offered to select one or more answers and add an answer of their own. The arithmetic mean of the results obtained was 1.1 , the median 1 , the mode 1 and the standard deviation 0.31. According to the results, it is obvious that pensioners and graduate professionals with no work experience would not do well in the interview for volunteer work, because $92 \%$ of responses gave preference to graduates with work experience. In the places foreseen for adding their own choice of a target group, no one added a choice of their own. Question ten was to find out what communication channels and techniques the respondents would use to address their volunteers. They were offered to select one or more answers and add an answer 
of their own. The arithmetic mean of the results obtained was 2 , the median 1 , the mode 1 and the standard deviation 2.23. Thus, the majority, 13 archives, selected social media (Facebook, Twitter, LinkedIn), an equal number of eight respondents opted for advertising via public posters and oral contacts respectively, six of them chose television, four newspapers, and one the radio. In the places foreseen for their own choice, no one wrote anything. Question eleven was not just about the possibilities of hiring volunteers, but also about respondents' perception of volunteer motivation and reward. This question also offered to select one or more answers and add their own question. It was found that one respondent did not answer the question at all, and almost all the others would reward their volunteers by giving them recommendations for the improvement of their career (13 respondents), 6 respondents would equally opt for presenting them with a commendation or to the press, and only four saw volunteer motivation and reward through ceremonies. Question twelve regarding respondents' expectations about running an archive more efficiently with a dedicated volunteer programme yielded the results presented in the following graph:

The arithmetic mean of the results obtained was 3.86, the median 4 , the mode 4 and the standard deviation 0.95 . Since five of fourteen archives responded that they strongly agreed with the item and four reported that they agreed, the following question arises: Why has

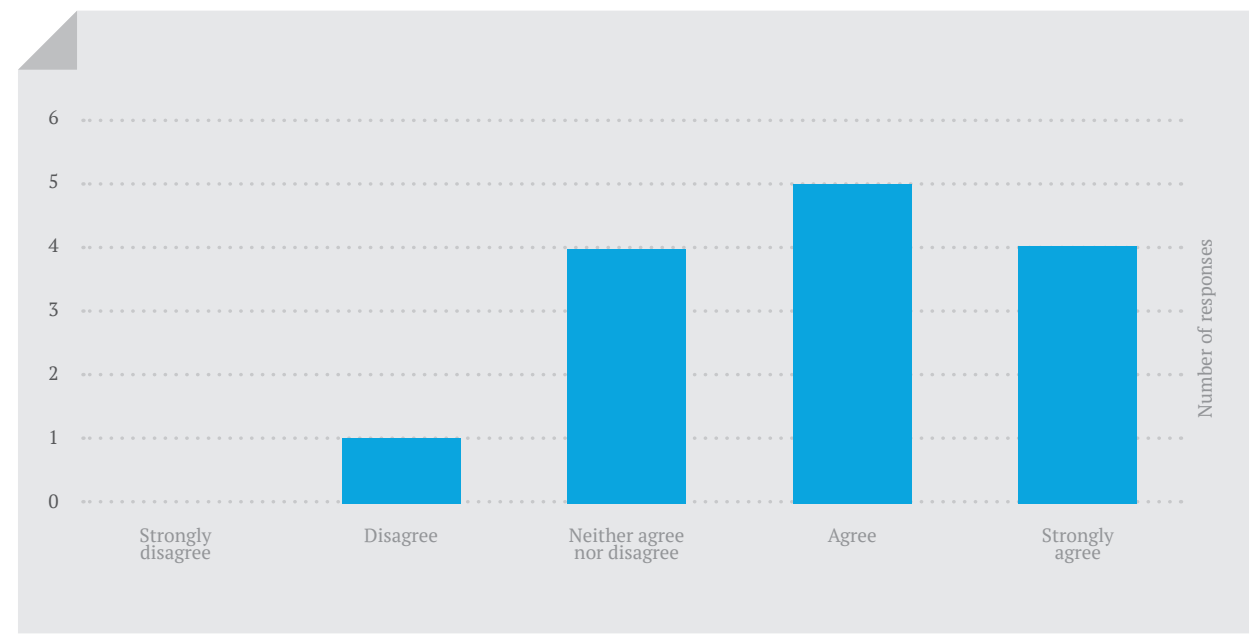

Figure 2: Rating of directors' attitude to the implementation of a volunteer programme with regard to the effects of the archive's activities 
nothing been done so far about starting the organized hiring of volunteers? Question 13 referred to the respondents' opinion about what their expectations were regarding the exact number of volunteer working hours in the archive. From the responses we can see that approximately two-thirds (64.3\%) of directors believed that volunteers should work within the hourly rate of a part-time job, which is in agreement with the results from previous answers, where volunteers were perceived as a threat to the archive material, and were thought to require a lot of effort and time for training. It was obviously good to limit the time of their presence in the institution. We also had in mind the evaluation of archive volunteer work, so we asked the directors according to what criteria control and volunteer work would be evaluated. They were asked to select one or more answers and add an answer of their own. The arithmetic mean of the results obtained was 1.5, the median 1 , the mode 1 and the standard deviation 1.22. As far as the evaluation criteria were concerned, the archives predominantly selected the invested hours of work, the amount of processed material (92.3\% of responses), and then getting along and the relationship with the management and permanent staff (61.5\% of responses). Obviously, the archives thought it was important not to spoil the current working atmosphere by introducing volunteers. However, the previous answers reported that the directors expected the work of volunteers to be effective, while they viewed the costs of supervision, training, work, etc. with less consideration.

The last three questions were asked to obtain a better insight into the previous education of the directors, regarding proper volunteer management, expectations that the National Archives Management should provide additional training and the desirable forms of such training. Thus, answering question fifteen which read: "Have you ever been taught how to manage volunteer work during your education?", none of the respondents testified to any course or seminar where they could have learned the basics of volunteer management. This fact raises concerns about the current Croatian archival practice, since volunteering can significantly help in achieving the objectives of archives. The following question asked for an overall estimation by the directors as to whether the National Archives Management should organize some forms of training to improve the competencies of directors in this area.

As can be seen from the Graph 3, 12.86\% of respondents wanted to learn more about volunteer management, but within a programme which would be offered by the National 


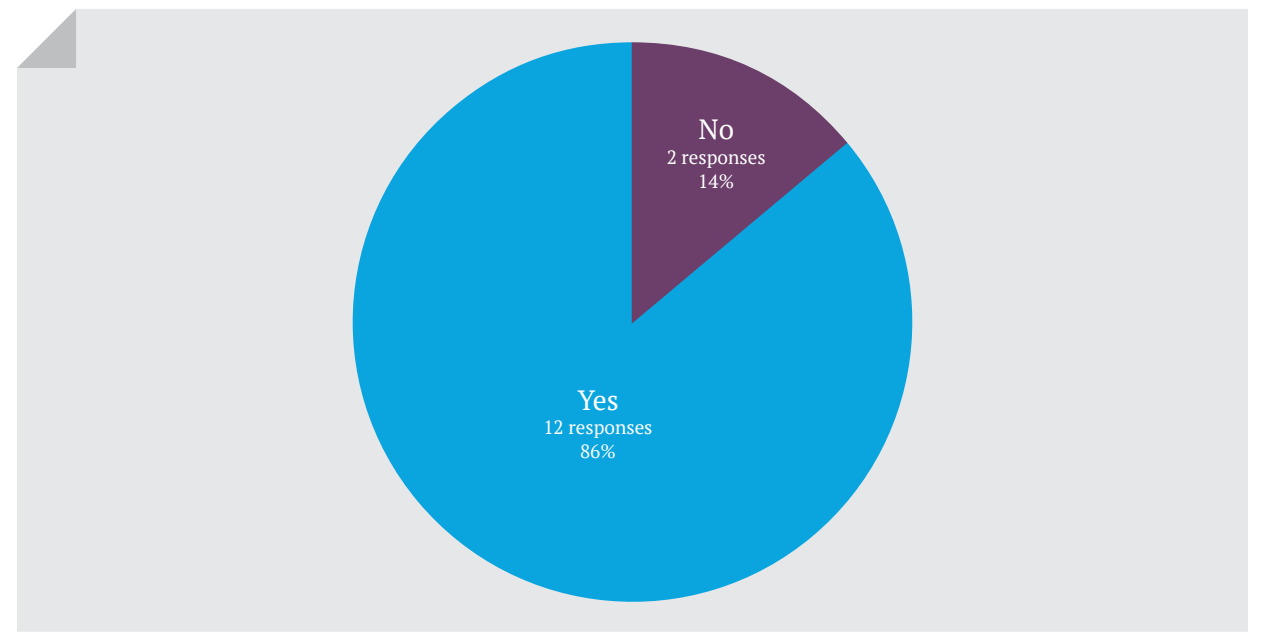

Figure 3: Attitudes of directors to the proposition that National Archives Management would do well to commit more resources to archivists' volunteer management education

Archives Management. In conclusion, the responses to the last question indicate that, in this case, the most suitable form of additional training would be workshops (80\% of responses) in contrast to seminars (20\%) and lectures (30\%).

\subsection{Recommendations for the Improvement of Future Archival Practice}

In order to improve the current Croatian archival practice, the research team recommends the following:

- If the archive did not previously use volunteers, it is necessary to primarily analyse the current situation and determine whether the archive is able to develop a volunteer programme.

- Directors would be wise to get in touch with the Society of Croatian Archivists and the Ministry of Culture in order to make a joint effort to wake Parliament from its long slumber as regulation of volunteer activities in archives through legislative action is desperately needed.

- Organize working meetings with the archivists of the institution on the possibilities of 
introducing volunteer engagement and the ways of organizing a volunteer programme.

- Investigate whether other heritage organizations (libraries, museums), which share the same geographical area with the archive, have already involved volunteers in their work.

- Take into account that archives frequently compete with other institutions, holders of cultural programs, so a programme should be designed which will emphasize the uniqueness of archives and the attractive features of archival material.

- At directors' conferences, a national consensus should be achieved on the need to implement a volunteer programme for each archive and the conclusions should be sent to the Croatian Council of Archives. Support of the national parent institution should be sought, as well as other relevant permits in order convince volunteers of the value of their contribution to the archive. Acknowledgement and support from the archive management will arouse archivists' enthusiasm to work with volunteers (Pavelin, 2016).

- Consult professionals for public relations, who may be very helpful to the archive, save archivists' time and effort and work with them respecting their contributions. By offering great support to the services for the promotion of the institution, archivists may be encouraged to be engaged in a number of tasks. By making their mission clear to disgruntled scholars and uninterested citizens alike, archives' visitorship will skyrocket.

- If Croatian archives are not able to obtain public relations support pro bono, a consensus should be achieved regarding the ways of establishing cooperation with external agencies.

- By engaging external agencies all the work cannot be transferred exclusively to external services, because the agency will regularly need someone from the archive to be in touch with. External associates cannot act without knowing what is going on in the archive.

\section{Conclusion}

Archives should be an advisory body comprised of the archive staff and communications managers who will manage volunteer work, including the evaluation of ideas for new projects as well. Volunteer management works with archivists in order to improve their relationship with volunteers, so that they can learn in which activities they may use them and what 
the benefits are of working with volunteers. Time for staff training and supervision, work space and security should be considered, as well as their implementation by holding and planning regular meetings. The staff time is the cost of successful volunteer programmes. The main task of the coordinator would be recruiting, interviewing and selecting volunteers, in cooperation with the supervisor. What seems to be a good system for the archivists is also a good programme for the volunteers. A good volunteer programme requires constant interaction between archivists and volunteers, as well as careful monitoring and control. Modern managers are supposed to have detailed knowledge of the methods of control and evaluation of volunteer contributions to the organization. Various interest groups that have authority over the management and distribution of the organizational resources want to know what results volunteer engagement achieves, and what is the long-term effect of volunteering on its survival. Non-profit organizations, in our case archives, are mainly financed by the state budget. The Croatian State Archive, with the introduction of the new projects based on volunteer management, give their country a good reason for a better insight into the positive effects of volunteering on the community, so that it may decide whether the expenditure for this purpose is justified. However, it is not advisable to look at the effects purely from an economic perspective, expressed in numerical units. A society which focuses on the archives and other stakeholders must also be aware of the qualitative characteristics of volunteering. Only together with the quantitative indicators do we include them in the final evaluation.

\section{Reference List}

- Bradsher, G. J. (1988). Archival Effectiveness. In: Bradsher, G. J., Pacifico, M. F. (Eds.), Managing Archives and Archival Institutions (pp. 253-264). London: The University of Chicago Press.

- Bunić, S. (2010). Volunteers in Libraries - opportunities and possibilities. Croatian Librarians' Herald, 53 (3-4), $115-124$.

- Connors, T. D. (2011). Evaluating the Volunteer Program: Contexts and Models. In: Connors, T. D. (Ed.), The Volunteer Management Handbook: Leadership Strategies for Success (pp. 363-379). New Jersey: Wiley.

- Connors, T. D. (2011). Risk Management in Volunteer Involvement. In: Connors, T. D. (Ed.), The Volunteer Management Handbook: Leadership Strategies for Success (pp. 323-360). New Jersey: Wiley.

- Cutlip, S. M., Center, A. H., Broom, G. M. (2003). Effective Public Relations. Zagreb: MATE d.o.o.

- Dearstyne, B. W. (1987). What Is the Use of Archives? A Challenge for the Profession. American Archivist, 50 (1), 76-87.

- Faletar, T. S. (2002). Volunteers in Museums. Informatica museologica, 33 (1/2), 52-56.

- Gregory, A. (2006). Public Relations: Planning and Managing Public Relations Campaigns. Zagreb: Croatian Association for Public Relations.

- Holmes, K., Smith, K. (2009). Training and Developing Volunteers. In: Holmes, K., Smith, K. (Eds.), Managing Volunteers in 
Tourism: Attractions, Destinations and Events (pp. 109-120). Oxford: Elsevier Linacre House.

- Ivanović, J. (2010). A Handbook on Archival Science. Zagreb: Croatian State Archives.

- Joyce, L. W. (1984). Archivist and Research Use. American Archivist, 47 (2), 124-133.

- Jurić, D. (2007). Managing Volunteers. Zagreb: Volunteers’ Centre Zagreb.

- Kotlar, V. Archives and Volunteers. Private e-mail. (6.02.2013.)

- Kurtz, M. J. (1988). Archival Management. In: Kurtz, M. J. (Ed.), Managing Archives and Archival Institutions (pp. 241-252). London: The University of Chicago Press.

- Laklija, M., Kolega, M., Božić, T., Mesić, M. (2011). Supervision Styles and Communication Processes from Supervisors' Perspective. Annual of Social Work, 18 (2), 365-382.

- Lamb, L. F., McKee, K. B. (2005). Applied Public Relations: Cases in Stakeholder Management. New York: Lawrence Erlbaum Associates, Inc.

- Pavelin, G. (2012). Efficiency of PR Communication in Establishing Links Between Archives and Students: Case Study of The State Archives in Zadar (Doctoral thesis). Zagreb: University of Zagreb.

- Pavelin, G. (2013). Planning Communication of Archives: Public Educational Programs and Information Needs of Croatian Educational System. Magistra Iadertina, 8 (1), 91-126.

- Pavelin, G. (2016). Archives, Media, Public Relations. Zadar: University of Zadar.

- Pavelin, G. (2016a). Public Relations as a Toolkit for Archives and Event Management. Zagreb: Alinea.

- Pavelin, G., Pletikosić, M. (2014). Communication Sensibility of Croatian State Archives. International journal of scientific research, 3 (1), 32-34.

- Pederson, A. (1993). User Education and Public Relations. In: Pederson, A. (Ed.), Keeping archives (pp. 306-349). Sydney: D.W. Thorpe and The Australian Society of Archivists, Inc.

- Randle, A. (2003). Volunteers and Friends: Recruitment, Management and Satisfaction. In: Freeman Finch, E. (Ed.), Advocating Archives: An Introduction to Public Relations for Archivists (pp. 83-97). New York: Scarecrow Press, Inc.

- Rjean, S. (1988). Guidelines for the teaching of marketing in the training of librarians, documentalists and archivists. Paris: General Informational Programme and UNISIST United Nations Educational Scientific and Cultural Organizations.

- Settanni, A. J. (1985). Toward a Usable Past: Historical Records in the Empire State. The Public Historian, 7 (4), $128-131$.

- Williams, C. (2006). Access, reference and advocacy. In: Williams, C. (Ed.), Managing Archives: Foundations, Principles and Practice (pp. 117-165). Oxford England: Chandos Publishing.

- Williams, C. (2006). Managing an archive services. In: Williams, C. (Ed.), Managing Archives: Foundations, Principles and Practice (pp. 201-230). Oxford England: Chandos Publishing.

\section{Internet Sources}

- Archives and Archives Records Act, Abridged version. Retrieved from: http://www.zakon.hr/z/373/Zakon-o-arhivskomgradivu-i-arhivima. January 15, 2015.

- SAA Council (2014). Best Practices for Volunteers in Archives. Retrieved from: http://www2.archivists.org/sites/all/files/ BestPract-Volunteers.pdf. December 12, 2016.

- Croatian Ministry of Culture, Hierarchy. Retrieved from: http://www.min-kulture.hr/default.aspx?id=135. May 15, 2014.

- Croatian Volunteering Act, Abridged version. Retrieved from: http://www.zakon.hr/z/258/Zakon-o-volonterstvu. December 11, 2016.

- Press Release, XLIX; Zagreb, June 20th 2012. Issue 8.3 (6). Retrieved from: http://www.culturenet.hr/UserDocsimages/ statistika\%202013/arhivi\%20 priopćenje\%202011.pdf. November 18, 2015.

- Web Portal to Croatian Culture, culturenet.hr. Retrieved from: http://culturenet.hr. November 18, 2015. 


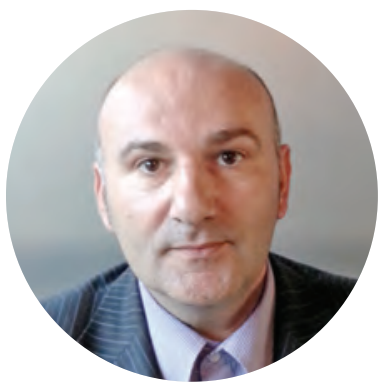

Goran Pavelin Roko Matanović

Goran Pavelin, PhD. His scientific expertise is based on research and advancement of Croatian cultural heritage and non-profit organizations that advocate its preservation, most notably archives. He has spent time arguing for the introduction of carefully crafted PR courses that would borrow from communication sciences and contemporary methods of research and be subject to meticulous evaluation. He has published a number of papers in foreign journals, 2 books and several chapters in international scientific books on the application of PR in an archival setting. His research deals with sports and cultural tourism and is often published abroad.

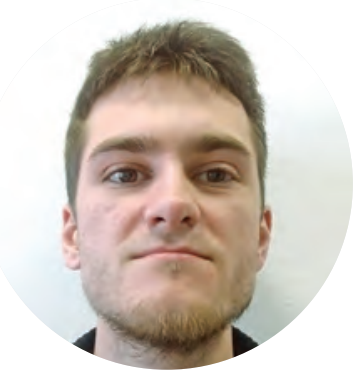

Roko Matanović is in his third year of studies for a bachelor's degree. His interests revolve around the study of communication, especially internet technology, social media and public relations. He has also delved into the application of statistics in research. Collaborating with highly skilled professors has put his skills to the test and taught him teamwork. He would like to improve his career prospects by enrolling in journalism and public relations for a master's degree as well as taking part in international student exchange programs. 